\title{
Methodological Difficulties in Normative Legal Acts Regulatory Impact Analysis in the Entrepreneurship Sphere in the Kyrgyz Republic Conditions
}

\section{Aliya Kalybaeva ${ }^{1}$, Zhypar Murzabekova ${ }^{2}$, Satkynai Nasbekova ${ }^{3}$, Anara Niyazova1, Andrei Ten ${ }^{4}$, Gulsara Kuldusheva5, Zhypargul Abdullaeva6* ${ }^{*}$}

\author{
${ }^{1}$ Department of Civil Law and Procedure, Kyrgyz-Russian Slavic University Named after B.N. Yeltsin, Bishkek, Kyrgyzstan \\ ${ }^{2}$ Department of Jurisprudence, International Academy of Management, Law, Finance and Business, Bishkek, Kyrgyzstan \\ ${ }^{3}$ Department of Business and Procedural Law, Kyrgyz National University Named after J. Balasagyn, Bishkek, Kyrgyzstan \\ ${ }^{4}$ International University of Central Asia, Jurisprudence Program, Bishkek, Kyrgyzstan \\ ${ }^{5}$ Department of the Theory and History of Government and Law, Osh State University, Osh, Kyrgyzstan \\ ${ }^{6}$ Science and Research Department, Osh State University, Osh, Kyrgyzstan \\ Email: ^jypar.science@oshsu.kg
}

How to cite this paper: Kalybaeva, A., Murzabekova, Z., Nasbekova, S., Niyazova, A., Ten, A., Kuldusheva, G., \& Abdullaeva, Z. (2021). Methodological Difficulties in Normative Legal Acts Regulatory Impact Analysis in the Entrepreneurship Sphere in the Kyrgyz Republic Conditions. Open Journal of Political Science, 11, 402-408. https://doi.org/10.4236/ojps.2021.113027

Received: March 20, 2021

Accepted: June 14, 2021

Published: June 17, 2021

Copyright $\odot 2021$ by author(s) and Scientific Research Publishing Inc. This work is licensed under the Creative Commons Attribution International License (CC BY 4.0).

http://creativecommons.org/licenses/by/4.0/

\begin{abstract}
Relevance in this article is practical analysis issues in the regulating impact connecting with its methodological problems appearing in this process. Authors are suggesting several recommendations about improvement of methodology in regulating impact analysis in the context of legal realities in the Kyrgyz Republic. The regulatory Impact Analysis tool allows to take into account position of entrepreneurs in preparation of regulatory documents at the development stage, those provisions may lead to administrative or financial business or costs to the government or society as a whole. Entrepreneurial activity in Kyrgyzstan today is intending to fulfill a very important goal for general government regulation process to ensure the compliance of the developed adopted normative legal acts with key tasks in the fields of government policy, the market economy, its basic mechanisms and requirements established by the methodology in RIA were described.
\end{abstract}

\section{Keywords}

Analysis, Regulating Impact, Normative Legal Act, Entrepreneurship Problem, Methodology

\section{Introduction}

Regulatory Impact Analysis (RIA) is the systematic identification and evaluation 
of the expected results of regulatory proposals, and the process of identifying, analyzing problems, defining the public intervention objectives, analyzing costs, benefits, and possible implementation options (Kupiec, 2015). RIA is used as a crucial instrument for improving the efficiency, effectiveness, transparency, and accountability of regulatory decision-making throughout Organisation for Economic Co-operation and Development (OECD) countries, and less frequently in developing countries (Jakupec \& Kelly, 2016; Adelle et al., 2015). The RIA tool allows to take into account the position of entrepreneurs in preparation of regulatory documents at the development stage, those provisions may lead to administrative or financial business or costs to the government or society as a whole; in different countries, the RIA can be different in terms of assessed regulations, procedures, terminology, and analysis methods (Application, 2017). Analysis of the regulatory impact of normative legal acts regulating relations arising in the field of entrepreneurial activity in Kyrgyzstan today is intended to fulfill a very important goal for the general government regulation process to ensure the compliance of the developed and adopted normative legal acts with the key tasks in the fields of government policy, market economy and its basic mechanisms. At the same time, in the practical sphere, many difficulties are associated with carrying out high quality, scientifically grounded, and methodologically correct analysis of the regulatory impact. In assessing the regulatory impact assessment effects role in the system of government regulation economy, a comparison was made of the content "regulatory impact assessment" that becoming an object of management, and also analyze the methodological basis for assessing the regulatory impact models of organization in monitoring and control the regulatory impact assessment quality (Turgel \& Panzabekova, 2018).

Entrepreneurship has not been researched well in the post-Soviet countries with transitional economies of Central Asia (CA) as part of developing countries. The Kyrgyz Republic (KR), better known as Kyrgyzstan (KG(Z)), was a part of the former Soviet Union as were its neighboring countries in Kazakhstan, Tajikistan, Turkmenistan and Uzbekistan (Tynaliev, 2014). Among entrepreneurs in Kyrgyzstan, who established production facilities, purchased equipment, employ a workforce, noted about importance and necessity in the protection of national and foreign investment, tax granting to reduce production costs, the establishment of measures towards a better balancing between import protection and export subsidy (Schröder \& Schröder, 2017). Research on the infrastructure relations on small and medium enterprise businesses in Kyrgyzstan indicates that informal relations prevailing over formal institutions; the Kyrgyz economy is dependent on informal players (Kapalova, 2014). "Demilgeluu Jashtar" project funding by USAID in Kyrgyzstan aims to train 400 young people qualified to undergo the entrepreneurship program and distribute grants to the most promising business ideas (University of Central Asia, 2021).

The regulatory impact analysis was introduced in the Kyrgyz Republic in 2007, the Government of Kyrgyz Republic adopted a decree "On the methodology for analyzing the regulatory impact of regulatory legal acts on the activities 
of business entities", in which methodology, the goals, objectives, and procedure for the analysis of regulatory impact were determined (RIA, 2021a). Some aspects in the analysis system formation and establishment of regulatory impact in conditions of the Kyrgyz Republic in the entrepreneurship sphere were described (Zhylkuchieva et al., 2021).

\section{Research Methods}

Using the documents available online, internet sources, and formal logical analysis method, we tried to highlight the most significant problems faced in practice to conduct the regulatory impact analysis in various areas. Research was designed by currently available methodologies for analyzing the regulatory impact legal acts on the business entity activities, approved in 2014, were aimed at ensuring a high-quality process of analyzing the regulatory impact; however, according to the Kyrgyz Republic representative experts assessments of the business community, the requirements practical implementation laid down in completing the least embodies expected results (Methodology for analyzing the regulatory impact of regulatory legal acts on the activities of business entities, approved by the Government of the Kyrgyz Republic, 2014).

\section{Goals and Objectives}

Considering the practical difficulties such as rationalizing and standardizing information, improving the border control, trade facilitation, arising in the conditions of the Kyrgyz Republic in terms of the regulatory impact analysis, it can be noted, firstly, the insufficient level of civil servants qualifications, whose duties are charged with performing the relevant analytical work (Khalikov, 2018). A vague understanding the goals and objectives of the regulatory impact analysis by performers lead to the so-called common mistakes, which are largely expecting positive effects in undertaken analysis. Such errors, as a rule, are associated with non-compliance with the methodological recommendations for analyzing the regulatory impact, which is incorporated within the specified methodology. In this regard, in addition to the human factor, methodological errors can be called as negative aspects that violate established procedures for the analysis of the regulatory impact (Venediktov et al., 2019).

For characterization of the most common methodological errors that can be found in the course of the regulatory impact analysis, firstly it is necessary to determine what exactly is meant by cognition methodology. We proceed from the fact, that analysis as a mental operation belongs to the system of cognitive processes in human consciousness, and directly depends on a person's ability to draw up and operate judgments, draw conclusions, build hypotheses, search for evidence and perform other operations aimed at achieving a unite goal (Ponukalin, 2003).

It should be noted that in the general theory of the methodology of scientific knowledge, methods of collecting scientific information and scientific thinking are distinguished, and we are more interested in the second group of methods, 
which traditionally include:

1) Methods of correct use of terms and their definition (methodology for introducing the term);

2) Methods of correctly finding the truth of a judgment, depending on its types (judgments truth methodology);

3) Methods of correctly posing questions, in particular, methods of correctly writing a scientific work (question methodology);

4) Methods of constructing inference from some judgments of others (methodology of causality);

5) Methods of correct analysis and construction of scientific theories (methodology of scientific analysis.

When applying each of the above methods, it is possible to make certain methodological errors, that is, the results of research actions and procedures performed in violation of the rules or laws of the methodology of scientific knowledge (research methodology) (Ponukalin, 2003).

The presence of methodological errors leads to a decrease in the quality of the scientific product, distortion of information, and, ultimately, to the unreliability of the scientific knowledge obtained (Ponukalin, 2003). Applying the general provisions on the methodology of cognition to the analysis of regulatory impact, we note that all of the above is true for the results that were obtained in the framework of the corresponding analytical work of the developed regulatory legal acts.

The most frequently encountered methodological problems when using the methodology of scientific analysis in the Kyrgyz Republic include the following groups of problems that were identified by us because of the analysis of documents formed by the relevant working groups.

\section{Problem Description}

This group of methodological errors can be attributed to situations when the very formulation of the problem to be identified in the analysis does not correspond to its description. Such a contradiction gives rise to incorrect premises for analytical work. In addition, a frequently encountered methodological flaw can be called the definition of the underlying problem as the absence of an appropriate regulatory legal act. The absence of a normative act itself is not a problem to be analyzed. Not always, the absence of a regulatory legal act can be characterized as a negative circumstance associated with the relevant field of business. In addition, this group of errors can be attributed to the incorrect definition of problems or its incorrect scaling (RIA, 2021b). In particular, situations are not uncommon when formulating or describing a problem, the views of individual stakeholders, parties, whose vision is necessary to understand the relevant situation, are not taken into account. This also includes the methodological difficulties that arise when it is necessary to determine the degree of government intervention to resolve the identified problem. This issue requires careful study, espe- 
cially in the context of the liberal economy course, which assumes minimal participation of the state apparatus in the regulation of individual relations in the field of business. It is necessary to pay attention to the fact that the above factors are directly dependent on each other. From how accurately the problem will be formulated, it will be obvious how justified is state intervention in its solution at one stage or another.

When conducting RIA by government agencies, in the overwhelming majority of cases, the following violations of the requirements established by the methodology for RIA allowed:

1) Wrong definition and description of problems at the stage of identifying problems, the wording of the problems does not correspond to the description of the indicated problem;

2) Definition of the root problem as "lack of a regulatory legal act". The lack of a regulatory legal act is not a problem;

3) Failure to disclose the scale of the problems or their incorrect definition; the lack of analysis of the views of stakeholders for each category: entrepreneurs, individuals, and their associations, government agencies and the impact of legal acts on their interests are not indicated;

4) Lack of evidence or grounds for government intervention in solving problems;

5) Lack of logical connection between stages;

6) Lack of legal, economic, and other analyzes, as well as the results of public discussions for an alternative regulation option;

7) Reflection of the position of only a state body or the state as a whole: there is no clear position of business entities, associations, and citizens;

8) Lack of positive and negative consequences for regulatory options: when describing the regulatory impact and implementation risks of each regulation option, the state bodies describe the consequences that are beneficial for the state or the government body; there are no descriptions of the negative impact and risks for the activities of business entities.

9) Lack of descriptions of the norms regulating entrepreneurial activity provided for in the draft NLA;

10) Lack of results of public discussion of the draft law;

11) Lack of public discussion of the RIA project (RIA, 2021b).

\section{Relevant Stages in Completion in the Regulatory Impact Analysis}

The business entity's position inadequate perception can also lead to a violation of the integrity in stage passages. This is due to regulatory impact analysis conducting by civil servants, and a priori reflecting the government position.

In this case, methodological problems appear to be a consequence of simple non-compliance with the established requirements to ensure a logical relationship between the stages (Ponukalin, 2003). In addition, the actual absence or in- 
sufficiency of legal or economic analysis, as well as the result of public discussion, lead to incorrect conclusions at certain stages of the analysis of the regulatory impact. Public discussion, in this case, is the most important component of effective analysis of regulatory impact, which is a manifestation of the active position in civil society about a particular issue.

\section{Improper Forecasting of the Consequences Adopting a Normative Legal Act for Stakeholders}

Here the methodological problem is directly related to the ability to see and find the relationship between intended action and expected consequence, its positive and negative properties that can affect the regulation of a particular area in entrepreneurial activity. As a rule, when calculating possible consequences, and circumstances that are important specifically for the government, but not for business entities taken into account, which is completely inconsistent with analysis spirit of the regulatory impact and the proclaimed goals facing it. Moreover, we can say that it is precisely under the consideration of the business entities' interests, and ultimate goals of the regulatory impact analysis, since the subjective needs of free market participants are the central element in goal setting.

\section{Conclusion}

Summing up the results of the study, we can conclude that the success of the analysis of regulatory impact directly depends on the quality of the methods used in its implementation, on the completeness and clarity of understanding by the relevant persons of the methodological foundations of scientific knowledge, which is the essence and reflects the objectives of the analysis of regulatory impact. The methodological complexities discussed must be addressed to provide a high quality and effective analysis of regulatory impact.

\section{Conflicts of Interest}

The authors declare no conflicts of interest regarding the publication of this paper.

\section{References}

(2014). Methodology for Analyzing the Regulatory Impact of Regulatory Legal Acts on the Activities of Business Entities, Approved by the Government of the Kyrgyz Republic. September 30, No. 559.

Adelle, C., Macrae, D., Marusic, A., \& Naru, F. (2015). New Development: Regulatory Impact Assessment in Developing Countries, Tales from the Road to Good Governance. Public Money and Management, 35, 233-238. https://doi.org/10.1080/09540962.2015.1027500

Application (2017). The Concept of Creating a Government System for Analyzing Regulatory Impact in the Context of the Integration of the Kyrgyz Republic into the EAEU (pp. 1-27).

Jakupec, V., \& Kelly, M. (2016). Development Aid: Regulatory Impact Assessment and Conditionality. Impact Assessment and Project Appraisal, 34, 319-329. 
https://doi.org/10.1080/14615517.2016.1228339

Kapalova, A. (2014). Small and Medium Enterprise Development in Kyrgyzstan: Informal Communications and the Role of Women (pp. 1-36). Institute of Public Policy and Administration Working Paper 25, Bishkek: University of Central Asia. https://doi.org/10.2139/ssrn.3023235

Khalikov, M. S. (2018). State Service in the System of Public Administration. Communicology Electronic Scientific Journal, 2, 14-21.

Kupiec, T. (2015). Regulatory Impact Analysis Practice in New Zealand in the Light of Models of Evaluation Use-Inspiration for the Polish Government. Central European Management Journal, 23, 109-128. https://doi.org/10.7206/mba.ce.2084-3356.144

Ponukalin, A. A. (2003). On the Methodology of Cognition. Bulletin of the Saratov State Technical University, 1, 159-167.

RIA Regulatory Impact Analysis (2021a). What Is Regulatory Impact Analysis? http://mineconom.gov.kg/ru/direct/5/50

RIA Regulatory Impact Analysis (2021b). Frequent Mistakes Made by RIA Developers When Conducting RIA. http://mineconom.gov.kg/ru/direct/5/31

Schröder, P., \& Schröder, E. (2017). Entrepreneurship in Kyrgyzstan: Adjustments to a Changing Economic Environment (51 p.). Bonn: Friedrich-Ebert-Stiftung e.V.

Turgel, I. D., \& Panzabekova, A. Zh. (2018). Assessment of Regulatory Impact in PostSoviet Countries: Results, Problems, Perspectives. Management Sciences, 8, 84-93. https://doi.org/10.26794/2404-022X-2018-8-2-84-93

Tynaliev, U. M. (2014). Is Individual Entrepreneurship Necessity or an Opportunity in the Kyrgyz Republic? A Panel Study. European Journal of Business and Economics, 9, 20-28. https://doi.org/10.12955/ejbe.v9i2.526

University of Central Asia (2021). Eight Entrepreneurs Win Funding to Start Businesses in Kyrgyzstan. https://www.ucentralasia.org/Resources/Item/2141/EN

Venediktov, D. S., Gabdullazyanova, K. R., \& Samitov, E. O. (2019). Human Factor in Russian Law: Theory and Practice. Colloquium Journal, 15, 9-12.

Zhylkuchieva, K., Kalybaeva, A., Nasbekova, S., Ten, A., Pak, N., Kuldysheva, G., \& Abdullaeva, Z. (2021). System Tasks for Assessing the Regulative Impact of Legal Acts in the Entrepreneurship Sphere. Open Journal of Social Sciences, 9, 373-379.

https://doi.org/10.4236/jss.2021.94028 